\title{
Expression of Receptor Tyrosine Kinases Epidermal Growth Factor Receptor and HER-2/neu in Synovial Sarcoma
}

\author{
Dafydd G. Thomas, M.D., Ph.D. ${ }^{1,2}$ \\ Thomas J. Giordano, M.D., Ph.D. ${ }^{1}$ \\ Donita Sanders, M.s. ${ }^{1}$ \\ Sybil Biermann, M.D. ${ }^{3}$ \\ Vernon K. Sondak, M.D. ${ }^{4}$ \\ Jonathan C. Trent, M.D., Ph.D. ${ }^{5}$ \\ Dihua Yu, M.D., Ph.D. ${ }^{5}$ \\ Raphael E. Pollock, M.D., Ph.D. ${ }^{5}$ \\ Laurence Baker, D.0. ${ }^{2}$
}

\begin{abstract}
${ }^{1}$ Department of Pathology, University of Michigan Health System, Ann Arbor, Michigan.

${ }^{2}$ Department of Internal Medicine, University of Michigan Health System, Ann Arbor, Michigan.

${ }^{3}$ Department of Orthopedic Surgery, University of Michigan Health System, Ann Arbor, Michigan.

${ }^{4}$ Department of Surgery, University of Michigan Health System, Ann Arbor, Michigan.

${ }^{5}$ Department of Surgical Oncology, The University of Texas M. D. Anderson Cancer Center, Houston, Texas.

Presented, in part, at the 7th Connective Tissue Oncology Society Meeting, West Palm Beach, Florida, November 1-3, 2001.
\end{abstract}

Supported, in part, by the Robert Urich Memorial Sarcoma Fund at the University of Michigan.

The authors thank the staff and patients of the Connective Tissue Oncology Program of the University of Michigan Comprehensive Cancer Center, without whom none of this work would be possible.

Dafydd G. Thomas is a Walther Cancer Institute Research Investigator and acknowledges their kind support.

Vernon Sondak's current address: Department of Cutaneous Oncology, H. Lee Moffitt Cancer Center, Tampa, Florida.

Address for reprints: Dafydd G. Thomas, M.D., Ph.D., Department of Pathology, M2242 Medical Science Building I, University of Michigan Cancer Center, 1301 Catherine Street, Ann Arbor, Ml 48109-0602; Fax: (734) 647-1358; E-mail: Thomasda@med.umich.edu

Received December 31, 2003; revision received September 1, 2004; accepted October 28, 2004.
BACKGROUND. Synovial sarcomas are high-grade soft tissue neoplasms often characterized by a biphasic spindle and epithelioid cell morphology. The majority of synovial sarcomas harbor a specific chromosomal translocation in which the proximal portion of the $S Y T$ gene at chromosome $18 \mathrm{q} 11$ is fused to the distal portion of one of several duplicated SSX genes (most notably SSX1 and SSX2) at chromosome Xp11. SYT/SSX1 translocations are seen in nearly three times as many synovial sarcomas as SYT/SSX2 translocations. Although the SYT/SSX2 fusion is usually associated with the monophasic disease pattern, the SYT/SSX1 fusion is present in tumors with biphasic or monophasic patterns. The SYT/SSX1 fusion gene is associated with more aggressive tumor growth and poor outcome. Despite advances in the therapy of local disease, distant metastasis remains the predominant cause of death. Accordingly, there is a need for alternate therapies, such as those recently developed against the receptor tyrosine kinases, such as epidermal growth factor receptor (EGFR) and HER-2/neu.

METHODS. Archival specimens of synovial sarcoma $(n=38)$ representing 30 patients were assessed for EGFR and HER-2/neu protein expression by standard immunohistochemical techniques. To validate the immunohistochemistry results, quantitative real-time polymerase chain reaction (Q-PCR) assays using either fresh and/or archival material was performed. The presence of gene amplification was determined by chromogenic in-situ hybridization.

RESULTS. EGFR and HER-2/ neu protein were detected by immunohistochemistry in 21 of $38(55.3 \%)$ and 20 of $38(52.6 \%)$ synovial specimens, respectively. EGFR immunoreactivity showed a granular and membranous pattern, whereas HER-2/ neu immunoreactivity demonstrated only a membrane pattern. Coexpression was observed in 13 of 38 specimens (34.2\%). HER-2/ neu expression by immunohistochemistry in synovial sarcomas was restricted to tumors with the SYT/SSX1 translocations. Of 6 specimens with SSX2 translocation, none (0\%) showed HER-2/ neu immunoreactivity and 1 (17\%) demonstrated EGFR expression. Q-PCR demonstrated the presence of mRNA for EGFR and HER-2/neu in 19 of 30 specimens (63.3\%) and 22 of 30 specimens (73.3\%), respectively. EGFR and HER-2/neu were expressed at low concentrations compared with the expression of glyceraldehyde 3-phosphate dehydrogenase (GAPDH). No evidence of gene amplification was observed.

CONCLUSIONS. EGFR and HER-2/neu are expressed in the majority of patients with SYT/SSX1 synovial sarcomas, albeit at low levels. Treatment with tyrosine kinase inhibitors may represent appropriate alternate therapy for these patients. Cancer 2005;103:830-8. (C) 2005 American Cancer Society.

KEYWORDS: synovial sarcoma, epidermal growth factor receptor, HER-2/neu, immunohistochemistry, chromogenic in situ hybridization, quantitative polymerase chain reaction.

Q ynovial sarcomas are malignant soft tissue tumors that occur - predominantly in children and young adults. ${ }^{1}$ They account for approximately $7-8 \%$ of all malignant mesenchymal tumors. ${ }^{2}$ Mor- 
phologically, they are biphasic with spindle and epithelioid/glandular cells, or monophasic, with a pure spindle cell pattern. ${ }^{3}$ The majority of tumors possess a specific chromosomal translocation, where the proximal part of SYT (18q11) is translocated to the distal portion of one of several duplicated SSX genes (most notably SSX1 and SSX2) on the short arm of chromosome X (Xp11). The SYT/SSX1 translocation is present in the majority $(\leq 75 \%)$ of patients and is associated with a poor prognosis. ${ }^{4,5}$ The SYT/SSX1 translocation is associated with both the biphasic and monophasic patterns, whereas the SYT/SSX2 translocation is usually associated with only the sarcomatous (monomorphic) morphology. Little is known of the functional role of these fusion proteins in tumorigenesis, although they are believed to play a role in the deregulation of transcriptional factors such as $\mathrm{CRB} / \mathrm{p} 300^{6}$ and hBRM/hSNF2a, a component of the SWI/SNF complex that regulates chromatin remodeling. ${ }^{7-9}$

Although surgery, radiotherapy, and adjuvant chemotherapy have improved the outcome of patients with local disease, management of distant metastasis remains problematic. Local disease recurrence, large tumors, lack of differentiation, older patient age, and pulmonary metastasis are all poor prognostic factors. ${ }^{10}$ Accordingly, there is need for alternate therapies, ${ }^{2}$ such as those recently developed against the receptor tyrosine kinases (RTK).

The human epidermal growth factor receptor (EGFR; ERBB) family of RTK is an important group of mediators responsible for cell proliferation, survival, adhesion, migration, and differentiation. ${ }^{11}$ The family comprises four distinct receptors: EGFR, HER-2, HER-3, and HER-4. EGFR, HER-3, and HER-4 are stimulated by a variety of ligands, whereas no known ligand has been identified for HER-2/neu. With the exception of HER-3, which lacks tyrosine kinase activity, all are transmembrane RTKs. ${ }^{12}$ Once activated by their respective ligands, they rapidly dimerize either as homodimers or heterodimers and exert their biologic activity through several different signal transduction pathways (for a review, see Yarden ${ }^{11}$ ). HER-2/neucontaining dimers are particularly resistant to endocytosis and, therefore, are more potent. ${ }^{13}$ EGFR is expressed in a variety of neoplasms including cervi$\mathrm{cal}^{14}{ }^{14}$ ovarian, bladder, ${ }^{15}$ and esophageal carcinomas. ${ }^{16}$ HER-2/ neu expression is amplified in a variety of primary human carcinomas, including breast, ${ }^{17}$ ovarian, endometrial, ${ }^{18}$ and lung carcinomas. ${ }^{19}$ HER2 / neu expression in breast and ovarian carcinomas is associated with a more aggressive phenotype, ${ }^{20}$ disease recurrence, ${ }^{21}$ poor overall survival, ${ }^{22}$ and chemotherapy resistance. ${ }^{23}$

Little is known about the expression of the ERBB family in synovial sarcomas. In a limited study of two cases of synovial sarcoma, strong EGFR membrane expression was found. ${ }^{24}$ Recently, ${ }^{25}$ analysis of eight monophasic synovial sarcoma specimens using spotted cDNA expression profiling demonstrated the clustering of EGFR with the SSX genes, suggesting that this RTK may be associated with synovial sarcoma-specific expression. In addition, two recent reports ${ }^{26,27}$ have demonstrated the immunopositivity of synovial sarcomas compared with other soft tissue sarcomas. Several recent reports have examined the expression of HER$2 /$ neu in synovial sarcoma. The first report by Allander et al., ${ }^{28}$ which investigated differences in gene profiling between synovial sarcoma and malignant fibrous histiocytoma (MFH) using array technology, demonstrated increased HER-2/neu expression in the synovial sarcoma cohort. The second article by Nuciforo et al. ${ }^{29}$ also demonstrated mRNA and protein expression in a small sample $(n=13)$ of synovial sarcomas. However, these two reports are in disagreement with an earlier study of a large cohort of pediatric sarcomas that showed that HER-2/neu overexpression was a rare event in mesenchymal tumors including synovial sarcoma. ${ }^{30}$ It would appear that the expression of EGFR and HER-2/ neu in synovial sarcomas is controversial.

To further investigate the possibility of EGFR and HER-2/ neu expression in synovial sarcoma, we examined a cohort of 30 patients by immunohistochemistry, chromogenic in situ hybridization (CISH), and real-time quantitative polymerase chain reaction (QPCR).

\section{MATERIALS AND METHODS \\ Tumor Specimens and Patients}

Fresh and formalin-fixed, paraffin-embedded tissue blocks (FFPE) of synovial sarcoma were obtained from the files of the Department of Pathology, University of Michigan Medical Center (Ann Arbor, MI) and from The University of Texas, M.D. Anderson Cancer Center (Houston, TX). Clinical history by chart review was obtained after approval was obtained from the institutional review board. The diagnosis of synovial sarcoma was confirmed as defined by World Health Organization criteria. ${ }^{31}$ After pathologic review, a tissue microarray was constructed from the most representative area using the methodology of Nocito et al. ${ }^{32,33}$

\section{Immunohistochemical Staining for Epidermal Growth Factor Receptor and HER-2/neu Expression}

Immunohistochemical staining was performed on a Dako autostainer (Dako, Carpinteria, CA) using Dako $\mathrm{LSAB}+$ and diaminobenzadine (DAB) as the chromogen. Deparaffinized sections of formalin-fixed tissue at 
$5-\mu \mathrm{m}$ thickness were labeled with EGFR (rabbit polyclonal antibody, 1:200, Zymed, South San Francisco, CA), HER-2/neu (rabbit polyclonal antibody, 1:400, Dako), or vimentin (mouse monoclonal antibody, 1:400, Dako). Protease K antigen retrieval was used before incubation with anti-EGFR. HER-2/neu sections did not require antigen retrieval. Microwave citric acid epitope retrieval was employed for vimentin. Appropriate negative (no primary antibody) and positive controls (overexpressing breast carcinoma) were stained in parallel with each set of tumors studied. The immunoreactivity of the membranes was scored by a four-tier (negative, low positive, medium positive, and high positive) modification of the normal grading scheme previously described by Wang et al. ${ }^{34}$ for RTK staining.

\section{SYT-SSX polymerase chain reaction}

The detection of the SSX fusion partner to $S Y T$ was determined using the method of Inagaki et al. ${ }^{35}$ All fusion gene products were confirmed by sequencing. Sequencing was performed within the University of Michigan Medical Center DNA sequencing core using an ABI 377 DNA sequencer (ABI, Foster City, CA).

\section{Total RNA Isolation and 5' Nuclease Assay}

Total RNA was isolated from FFPE tissue specimens ( $n$ $=30$ ) using the Ambion paraffin block RNA isolation kit (Ambion, Austin, TX) in accordance with the manufacturer's protocol or from fresh tissue specimens ( $n$ $=10$ ) using the TriZol method.$^{36}$ cDNA was synthesized from $1 \mu \mathrm{g}$ RNA using a first-strand synthesis kit for reverse transcription-PCR (Retroscript, Ambion) with random decamer primers.

The relative abundance of each mRNA species was assessed using the $5^{\prime}$ fluorogenic nuclease assay to perform Q-PCR. The principles of this assay have been reviewed elsewhere. ${ }^{37}$ PCR primers and FRET probe (TaqMan) for EGFR and HER-2/neu were obtained from Biosource (Camarillo, CA). The glyceraldehyde 3-phosphate dehydrogenase (GAPDH) primers and probes were obtained from Applied Biosystems (Foster City, CA). Q-PCR using a SmartCycler (Cepheid, Sunnyvale, CA) was performed in duplicate in $30-\mu \mathrm{L}$ reaction volumes consisting of $1 \times \mathrm{Q}$ PCR SuperMix-UDG reaction mix (Invitrogen, Carlsbad, CA) supplemented with the appropriate magnesium concentration for the primer/probe set employed. The reaction conditions were $50{ }^{\circ} \mathrm{C}$ for 120 seconds, $95^{\circ} \mathrm{C}$ for 10 minutes, followed by 60 cycles of $95{ }^{\circ} \mathrm{C}$ for 15 seconds and $60^{\circ} \mathrm{C}$ for 1 minute. Absolute expression of mRNA species was calculated using a standard curve generated from known concentrations of commercially available plasmids containing fulllength cDNA inserts (Invitrogen). Results are expressed as number of copies of EGFR or HER-2/ neu mRNA per 10,000 copies of GAPDH mRNA. RNA expression data have demonstrated that GAPDH expression is fairly constant in synovial sarcomas (results not shown). PCR products were resolved by polyacrylamide gel electrophoresis using $8 \%$ gels and stained with SYBR Green I nucleic acid gel stain (Ficcol Marine Colloid [FMC], Rockland, ME) and photographed under ultraviolet conditions. A breast tumor was also extracted under identical conditions and run in parallel as a positive control.

\section{Chromogenic In Situ Hybridization}

The CISH assay was performed using the EGFR and HER-2/ neu DNA probe kits (Zymed). CISH is a recently described technique analogous to fluorescent in-situ hybridization (FISH), but which uses a colorimetric end point. ${ }^{38}$ It is equivalent to FISH in its sensitivity and specificity ${ }^{39}$ but does not require the specialized fluorescent microscope used with FISH analysis. Briefly, deparaffinized sections were microwave pretreated for 10 minutes with the CISH pretreatment buffer (SPOTlight tissue pretreatment kit, Zymed) and digested for 5 minutes at $37^{\circ} \mathrm{C}$ with pepsin according to the manufacturer's instructions. Subsequently, the sections were washed with water, dehydrated with graded ethanol, and air-dried. The ready-to-use digoxigenin-labeled EGFR or HER-2/ neu probes and the biotin-labeled chromosome 7 centromer and chromosome 17 centromer probes were separately applied to the center of a cover slip and placed on the tissue section. After sealing the edges of the cover slip with rubber cement, the tissue section and probes were denatured for 10 minutes at $95{ }^{\circ} \mathrm{C}$ by placing the slides in the slide block of the PCR machine (MJ Research, Watertown, MA). Hybridization was performed overnight in a humid chamber at $37^{\circ} \mathrm{C}$. The stringency wash was done with $0.5 \%$ standard saline citrate at $75-80{ }^{\circ} \mathrm{C}$ for 5 minutes. Endogenous peroxidase activity and nonspecific protein binding were blocked by incubation with $0.6 \% \mathrm{H}_{2} \mathrm{O}_{2}$ in methanol for 30 minutes and CAS-block for 30 minutes. Sections were incubated with either mouse antibiotin (Vector, Burlingame, CA, 1:50, 30 minutes) or mouse antidigoxigenin (Roche Diagnostics, Indianapolis, IN, 1:50, 30 minutes). Immunohistochemical staining was completed using Dako Envision+ and DAB as the chromogen on the Dako autostainer. Tissue sections were counterstained with hematoxylin and mounted. Appropriate gene-amplified breast tumor controls were included in each run. Each section was evaluated at $\times 400$ and $\geq 30$ cells were counted for the presence of the specific probe and the 

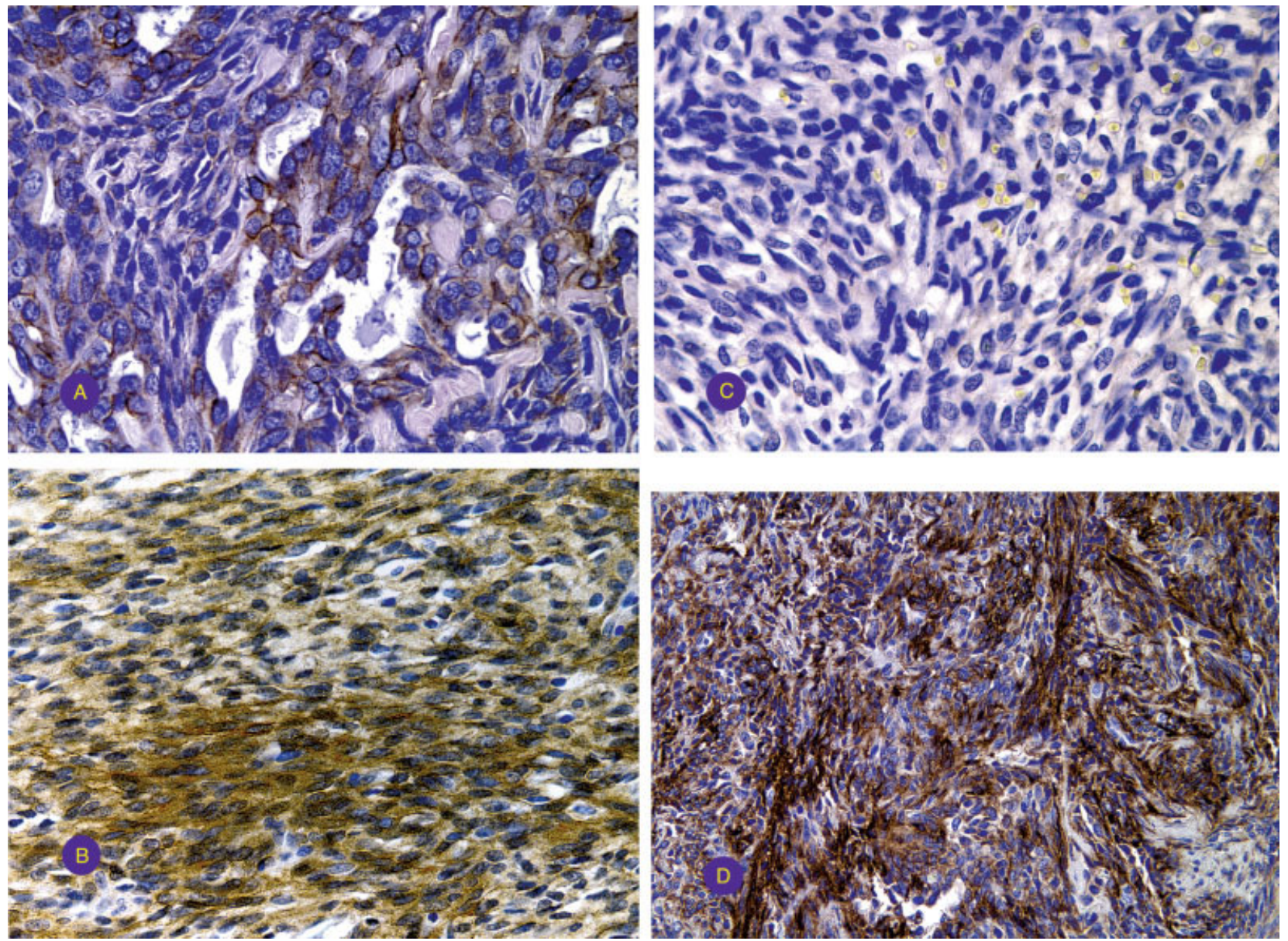

FIGURE 1. Immunohistochemical staining for epidermal growth factor receptor (EGFR) and HER-2/neu expression in synovial sarcoma. (A) A 31-year-old female with a right groin lesion expressing the SYT/SSX1 translocation, epithelioid morphology.. (B) A 31-year-old male with a right ankle lesion with SYT/SSX1 translocation, spindle cell pattern. (C) A 45-year-old male with a left buttock lesion. Posttherapy specimen with SYT/SSX2 translocation, demonstrating monophasic sarcomatoid morphology. (D) A 47-year-old male with a left knee lesion with SYT/SSX1 translocation, spindle cell pattern.. Anti-HER-2/neu avidin-biotin-peroxidase complex/hematoxylin staining (A-C); anti-EGFR, avidin-biotin-peroxidase complex/hematoxylin, (D). Original magnification $\times 200$ (B); $\times 400$ (A,C,D).

satellite probe for the chromosome 7 centromer and the chromosome 17 centromer.

\section{RESULTS \\ Clinicopathologic Data}

Thirty-eight specimens of synovial sarcoma cases representing 30 patients were used in the current study. The patients had a mean age of 33 years (range, 7-70 years) and the male-to-female ratio was 13:17. There were 22 specimens of primary tumors, 7 specimens of recurrent tumors, and 9 specimens of pulmonary metastatic tumors. There were 24 tumor specimens with $S Y T / S S X 1$ fusion genes and 6 tumor specimens with SYT/SSX2 fusion genes. The SSX1 group contained 18 tumor specimens with biphasic morphology and 6 specimens with monophasic morphology. The SSX2 group contained five monophasic and a single biphasic tumor specimen.

\section{Expression of the Epidermal Growth Factor Receptor and HER-2/neu Protein in Synovial Sarcoma by Immunohistochemistry}

Immunohistochemical analysis of 38 synovial sarcoma samples representing primary and metastatic lesions using the anti-HER-2/neu polyclonal antibody demonstrated the characteristic membranous staining associated with membrane-bound RTK in 20 of 38 (52.6\%) specimens (Fig. 1A,B). There were no differences in the quality of staining between epithelioid regions (Fig. 1A) and areas demonstrating spindle cell morphology (Fig. 1B). The majority of immunopositive tumor specimens demonstrated focal low to medium intensity $(1+$ to $2+)$ when compared with the 
$3+$ (high) staining intensity of the positive control. Only one specimen demonstrated the intense staining pattern observed with the control. All positive and negative immunohistochemical controls were appropriate. None of the six patients with the SYT/SSX2 phenotype demonstrated immunohistochemical reactivity for HER-2/ neu (Fig. 1C).

Nine patients with multiple biopsy and resection specimens were analyzed for the expression of HER-2/ neu with the objective of determining if there was a gain of the RTK expression over time. Only one patient demonstrated a gain of HER-2/ neu expression, whereas another patient demonstrated a loss of HER-2/ neu expression. The remainder of the patients demonstrated no change in their receptor status. Immunohistochemical analysis of 38 synovial sarcoma specimens representing primary and metastatic lesions using the anti-EGFR polyclonal antibody demonstrated the characteristic membranous staining associated with membranebound tyrosine kinases in 21 of 38 (55.3\%) specimens (Fig. 1D) in addition to focal granular immunoreactivity. All tumor specimens demonstrated focal low to strong immunoreactivity when compared with the strong staining intensity of the positive control. Stronger staining occurred in spindle cell areas compared with the epithelioid areas. All positive and negative immunohistochemical controls were appropriate.

Coexpression of EGFR and HER-2/ neu occurred in 13 of 38 synovial sarcoma specimens studied (46\%).

\section{Absence of Epidermal Growth Factor Receptor and HER- 2/neu Genomic Amplification in Synovial Sarcoma by Chromogenic In Situ Hybridization}

None of the 30 tumor specimens studied by CISH showed genomic amplification of the EGFR or HER-2/ neu oncogene by the CISH assay. Representative results are shown in Figure 2.

\section{Expression of Epidermal Growth Factor Receptor andHER-2/neu using Quantitative-Polymerase Chain Reaction Assay}

The presence of mRNA for EGFR and HER-2/neu was demonstrated in 19 of 30 specimens (63.3\%) and in 22 of 30 specimens $(73.3 \%)$, respectively. All of the tumor specimens with mRNA for EGFR or HER-2/neu by QPCR demonstrated a relative concentration of the message below the $\mathrm{C}_{\mathrm{T}}$ for $G A P D H$. A representative exponential curve for the two RTK and GAPDH is seen in Figure 3. Several tumor specimens expressed a message for HER-2/neu at extremely low levels and consequently failed to reach $\mathrm{C}_{\mathrm{T}}$, even though there was an exponential curve for GAPDH amplification (Fig. 3).

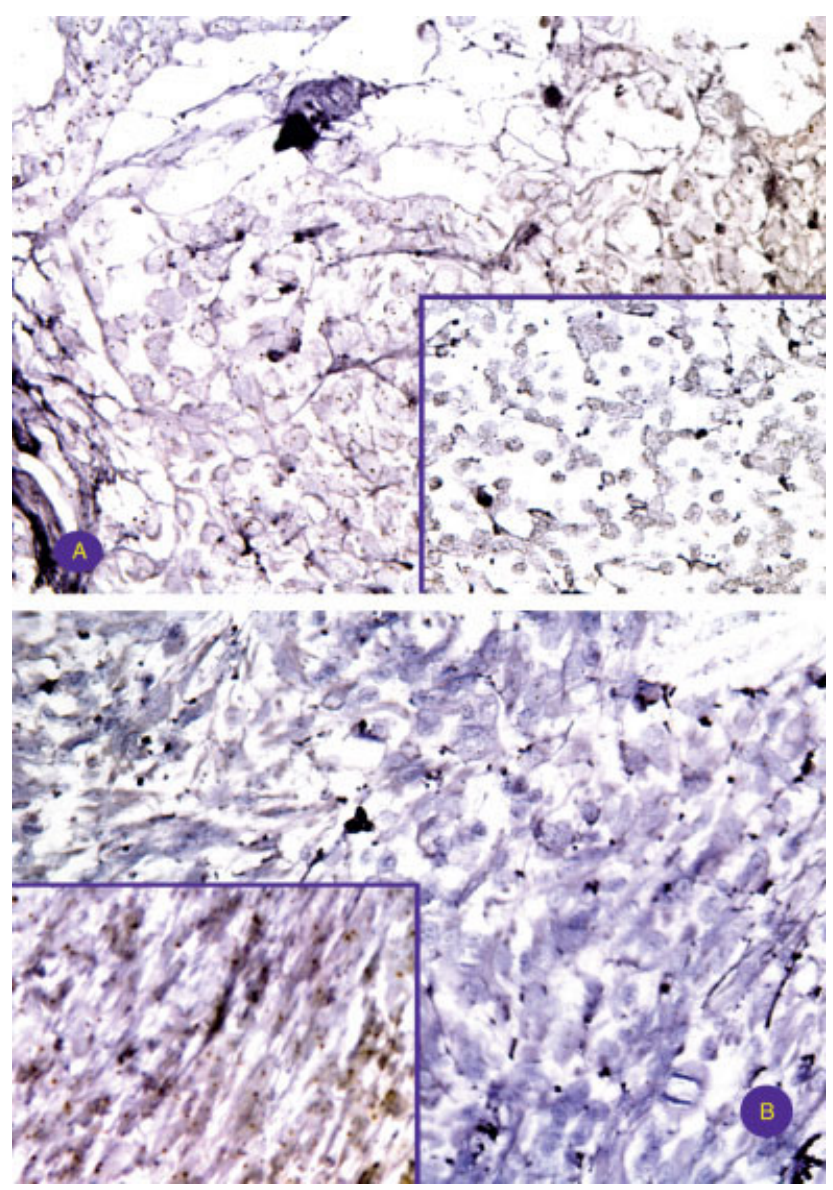

FIGURE 2. Chromogenic in situ hybridization (CISH) for epidermal growth factor receptor (EGFR) and HER-2/neu in synovial sarcoma samples. Sections were stained for the presence of EGFR and HER-2/neu gene amplification by CISH. (A) A synovial sarcoma with one or two clearly identifiable copies (brown dots) of HER-2/neu gene. (Inset:) A synovial sarcoma section with one or two brown spots representing a normal chromosome 17 karyotype. This demonstrates a nonamplified HER-2/neu gene. (B) A synovial sarcoma section with one or two clearly identifiable copies of the EGFR gene (brown dots). (Inset:) A synovial sarcoma section with one or two brown spots representing a normal chromosome 7 karyotype. This demonstrates a nonamplified EGFR gene. All sections were counterstained with hematoxylin. Original magnification $\times 400$.

The absolute expression of EGFR and HER-2/neu compared with GAPDH was EGFR, $600 \pm 205$ copies per 10,000 copies of GAPDH mRNA $(n=10)$ and HER-2/ $n e u, 4025 \pm 716$ copies per 10,000 copies of GAPDH mRNA $(n=10)$. Similar values were obtained for mRNA obtained from FFPE tissue blocks. These values indicate that EGFR and HER-2/neu mRNA are expressed at very low concentrations in synovial sarcoma cells. A parallel Q-PCR assay of an HER-2/neuimmunoreactive breast tumor demonstrated an overabundance of message relative to the reference gene (GAPDH; results not shown). 


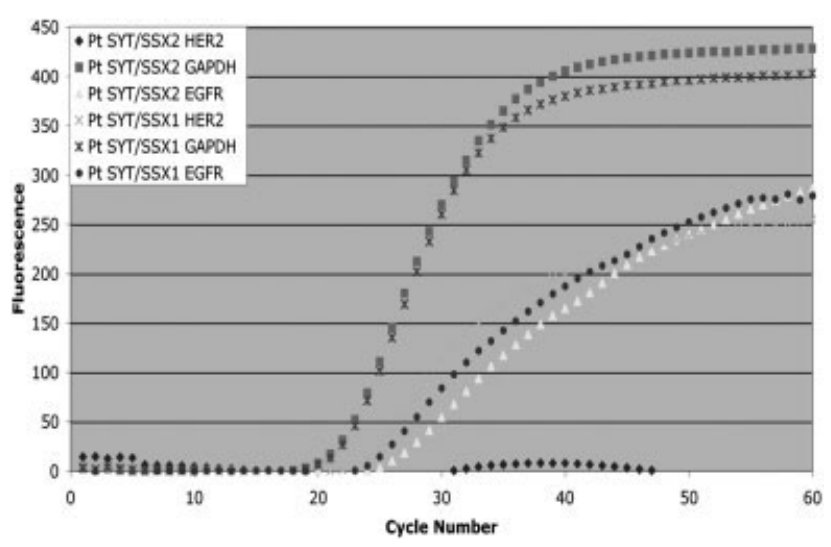

FIGURE 3. Relative epidermal growth factor receptor (EGFR), HER-2/neu, and glyceraldehyde 3-phosphate dehydrogenase (GAPDH) mRNA expression by real-time qualitative $\mathrm{PCR}(\mathrm{Q}-\mathrm{PCR})$ in two specimens of synovial sarcoma. Total RNA was isolated from fresh or formalin-fixed, paraffin-embedded tissue sections and subjected to Q-PCR. Synovial sarcoma specimen with the SYT/ SSX1 phenotype demonstrates expression of HER-2/neu mRNA, whereas the tumor specimen expressing the SYT/SSX2 translocation demonstrates very low concentrations of mRNA for HER-2/neu. Both specimens demonstrate expression of EGFR and GAPDH.

\section{Correlation of Receptor Tyrosine Kinase Immunoreactivity with the SYT/SSX Phenotype}

When SSX status was correlated with EGFR expression, 17 of 24 samples $(71 \%)$ were positive in patients with SSX1 fusion proteins, whereas only 1 of 6 patients (17\%) with the SSX2 fusion genes expressed EGFR immunopositivity. This patient demonstrated the only biphasic morphology tumor. HER-2/neu was present in $54 \%$ of the samples, all of which possessed the SYT/SSX1 phenotype. No tumor specimens with the SYT/SSX2 phenotype demonstrated immunoreactivity for HER-2/ neu.

\section{Correlation of Receptor Tyrosine Kinase Immunoreactivity with Gender, Age, and Metastasis Status}

No correlation was observed between either EGFR or HER-2/ neu mRNA or protein expression and age, gender, or metastatic status. This is in contrast to the study of Nuciforo et al. ${ }^{29}$

\section{Correlation of Receptor Tyrosine Kinase Immunoreactivity and mRNA Concentration}

A statistically significant association was demonstrated between protein expression and mRNA levels $(P<0.01)$ for both EGFR and HER-2/ neu in samples of synovial sarcoma possessing the SYT:SSX1 translocation. Medium to high-intensity immunopositivity (2$3+$ ) corresponded with an absolute Q-PCR value of 790 and 2290 copies of the EGFR and HER-2/neu, respectively. Low-intensity immunopositivity (1+) corresponded to an absolute value of 350-780 for EGFR and 510-2000 for HER-2/neu. Below these values, immunohistochemistry was negative.

\section{DISCUSSION}

In an earlier report, we demonstrated the absence of immunohistochemical staining for HER-2/neu in osteosarcomas. ${ }^{40}$ In the current report, we analyzed 38 samples of synovial sarcoma representing 30 patients for the expression of EGFR and HER-2/ neu RTKs using immunohistochemical and molecular methods and demonstrated expression of the genes, albeit at relatively low levels in the majority of cases. These results confirm the findings previously reported by Allender et al., ${ }^{28}$ Gusterson et al., ${ }^{41}$ Nielsen et al., ${ }^{25}$ and Nuciforo et al. ${ }^{29}$ In contrast to all of these reports, there was no differentiation of staining intensity between the epithelioid and sarcomatous elements in our samples. These results contrast with an earlier immunohistochemical survey of sarcomas and small round cell tumors of childhood, ${ }^{30}$ in which none of the synovial sarcomas studied $(n=6)$ demonstrated immunohistochemical staining for HER-2/neu. Intriguingly, Nuciforo et al. ${ }^{29}$ showed that the female members of the cohort did not have high protein expression compared with the male members of the cohort. However, they did not discuss further this noteworthy finding. We saw no correlation between gender and expression of either RTK mRNA or protein.

The difference between these studies could be due, in part, to the few synovial sarcoma samples examined and/or to the different antibodies used. Furthermore, unusual immunohistochemical staining patterns may lead to erroneous interpretation. Although immunohistochemistry is a routine laboratory technique that offers several advantages compared with other assays measuring protein expression, ${ }^{42}$ some disadvantages should be noted. First, the results of immunohistochemistry may be influenced by both the length and method of fixation as well as by the degree of antigen retrieval. ${ }^{43}$ Second, the results are clearly antibody dependent. Press et al. ${ }^{44}$ evaluated a panel of 28 antibodies (7 polyclonal antibodies and 21 monoclonal antibodies) on 187 FFPE breast tumor specimens, previously shown to be HER-2/neu positive, and demonstrated that the ability to detect HER$2 /$ neu-positive cells varied from $6 \%$ to $82 \%$. Gancberg et al. ${ }^{45}$ have also demonstrated similar specificity and sensitivity results. Third, intraobserver reproducibility is a problem, even with standardized reference material. ${ }^{46}$ In breast tumor specimens, HER-2/neu oncogene amplification typically has been associated with 
HER-2/ neu overexpression as evidenced by membrane staining. ${ }^{44,47,48}$

Oncogenic progression in sarcomas can be separated into two distinct groups cytogenetically, ${ }^{49}$ i.e., 1 ) sarcomas with a single, distinct chromosomal translocation, such as synovial sarcoma (t18:X)(q11;q11), alveolar rhabdomyosarcoma (t 2:13)(q35;q14), myxoid chondrosarcoma (t 9:22)(q22;q12), Ewing sarcoma (t 11:22) (q24;q12), clear cell sarcoma (t 12:22) (q13-q14; q12), dermatofibrosarcoma protuberans (DFSP) [ring 17 or $\mathrm{t}(17 ; 22)$ (q24;q12)], and desmoplastic small round cell tumor (DSRCT) (t 11:22)(p13;q25); and 2) sarcomas with complex karyotypes. These complex sarcomas are the results of multiple genetic alterations, each of which results in a biologic advantage for the malignant cell. Conversely, sarcomas such as synovial sarcoma rely on a single genetic change that is the seminal event and that has a profound affect on the malignant cells phenotype.

We speculate on the contribution of the SYT/SSX fusion type to the expression of these two RTKs. To understand the contribution of the SYT/SSX fusion type to the translation regulation of EGFR and HER2/neu expression, it is necessary to know about the normal function of the two gene products. The $S Y T$ gene codes for a protein with two functional domains: an amino terminal, which is conserved in the synovial sarcoma fusion proteins, and a C-terminal QPGY domain that functions as a transcriptional activator. ${ }^{50,51}$ Native SYT associates with p300/CBP in $\mathrm{G}_{1}$ arrested cells, resulting in the activation of $\beta 1$ integrin. ${ }^{52}$ Activated $\beta 1$ integrin regulates cell adhesion. The SSX group of genes on chromosome $\mathrm{X}$ encode proteins that are expressed strongly in normal thyroid and testes $^{53}$ in addition to malignant tumors, such as melanomas. ${ }^{54}$ These proteins contain an abundance of charged amino acids, a possible tyrosine phosphorylation site, and strong homology with a Kruppel-associated box (KRAB). The KRAB box has been implicated in transcriptional repression. In the SYT/SSX fusion proteins, the binding of SYT to p300/CBP is retained whereas the adhesion function is lost. ${ }^{52}$ The N-terminal KRAB box is also lost. Thus, the SYT/SSX fusion protein lacks zinc fingers responsible for protein-DNA interaction but contains strong motifs for proteinprotein interaction. It is possible that SYT/SSX mediates its action through modulation of other proteins responsible for transcription and translation. Several reports have localized the SYT/SSX fusion protein to the nucleus ${ }^{55}$ and described its role in homeotic gene silencing $^{56}$ and also its interaction with hBRM/ hSNF2 $\alpha$, a component of the SWI/SNF complex that regulates chromatin remodeling. ${ }^{51,57,58}$ The SYT/SSX fusion protein also binds to the p300/CBP complex, which has a role in the transcriptional regulation of HER-2/neu. ${ }^{6}$ It is too premature to speculate how these results correlate with our findings. Our results demonstrate the almost ubiquitous transcription of the gene for EGFR and HER-2/neu but suggest that there is a lack of translation regulation, especially in synovial sarcoma specimens containing the SYT/SSX1 fusion gene. This is surprising considering that SSX1 and SSX2 are nearly identical in amino acid composition. ${ }^{53}$ Furthermore, it is not suggested that the SYT/ SSX fusion protein is directly responsible for this lack of translational regulation but that it is certainly worthy of further study.

Because of the few specimens, especially specimens of synovial sarcoma with the SYT/SSX2 fusion product, it was not possible to determine if EGFR or HER-2/ neu oncoprotein or their respective mRNA are independent prognostic factors. Thus, a study of a larger group of patients with synovial sarcoma would be needed to assess the prognostic importance of EGFR and HER-2/ neu expression. It appears that unlike breast tumors, there is no evidence of receptor gene amplification and protein overexpression. However, the coexpression of EGFR and HER-2/neu may suggest that even in the presence of low concentrations of both RTKs, cooperative synergism may be an important tumorigenesis event.

In summary, our results, although they represent a small sample population, demonstrate that EGFR and HER-2/neu expression may represent an important molecular event in the oncogenesis of synovial sarcoma. Furthermore, the use of targeted therapy, such as small molecule inhibitors, which currently are under development, against either or both of the receptors may represent a viable therapeutic alternative.

\section{REFERENCES}

1. Weiss SW, Goldblum J. Enzinger and Weiss's soft tissue tumors. 4th ed. St. Louis, MO: Mosby, 2001.

2. Brennan FM, Casper ES, Harrison LB. Soft tissue sarcoma. In: DeVita VT, Hellman S, Rosenberg SA, editors. Cancer: principles and practice of oncology. 5th ed. Philadelphia: Lippincott-Raven, 1997:1738-1789.

3. Fisher C. Synovial sarcoma. Ann Diagn Pathol. 1998;2:401421.

4. Kawai A, Woodruff J, Healey JH, Brennan MF, Antonescu CR, Ladanyi M. SYT-SSX gene fusion as a determinant of morphology and prognosis in synovial sarcoma. $N$ Engl J Med. 1998;338:153-160.

5. Inagaki H, Nagasaka T, Otsuka T, Sugiura E, Nakashima N, Eimoto T. Association of SYT-SSX fusion types with proliferative activity and prognosis in synovial sarcoma. Mod Pathol. 2000;13:482-488.

6. Chen H, Hung MC. Involvement of co-activator p300 in the transcriptional regulation of the HER-2/neu gene. $J$ Biol Chem. 1997;272:6101-6104. 
7. Kato H, Tjernberg A, Zhang W, et al. SYT associates with human SNF/SWI complexes and the C-terminal region of its fusion partner SSX1 targets histones. J Biol Chem. 2002;277: 5498-5505.

8. Thaete C, Brett D, Monaghan P, et al. Functional domains of the SYT and SYT-SSX synovial sarcoma translocation proteins and co-localization with the SNF protein BRM in the nucleus. Hum Mol Genet. 1999;8:585-591.

9. Nagai M, Tanaka S, Tsuda M, et al. Analysis of transforming activity of human synovial sarcoma-associated chimeric protein SYT-SSX1 bound to chromatin remodeling factor hBRM/hSNF2 alpha. Proc Natl Acad Sci USA. 2001;98:38433848.

10. Bergh P, Meis-Kindblom JM, Gherlinzoni F, et al. Synovial sarcoma: identification of low and high risk groups. Cancer. 1999;85:2596-2607.

11. Yarden Y. The EGFR family and its ligands in human cancer. signalling mechanisms and therapeutic opportunities. Eur J Cancer. 2001;37(Suppl. 4):S3-S8.

12. Ullrich A, Schlessinger J. Signal transduction by receptors with tyrosine kinase activity. Cell. 1990;61:203-212.

13. Lenferink AE, Pinkas-Kramarski $R$, van de Poll ML, et al. Differential endocytic routing of homo- and hetero-dimeric ErbB tyrosine kinases confers signaling superiority to receptor heterodimers. EMBO J. 1998;17:3385-3397.

14. Kersemaekers AM, Fleuren GJ, Kenter GG, et al. Oncogene alterations in carcinomas of the uterine cervix: overexpression of the epidermal growth factor receptor is associated with poor prognosis. Clin Cancer Res. 1999;5:577-586.

15. Dorkin TJ, Robson CN, Neal DE. The molecular pathology of urological malignancies. J Pathol. 1997;183:380-387.

16. Nemoto T, Ohashi K, Akashi T, Johnson JD, Hirokawa K. Overexpression of protein tyrosine kinases in human esophageal cancer. Pathobiology. 1997;65:195-203.

17. Natali PG, Nicotra MR, Bigotti A, et al. Expression of the p185 encoded by HER2 oncogene in normal and transformed human tissues. Int J Cancer. 1990;45:457-461.

18. Cirisano FD, Karlan BY. The role of the HER-2/neu oncogene in gynecologic cancers. J Soc Gynecol Invest. 1996;3:99105.

19. Bongiorno PF, Whyte RI, Lesser EJ, Moore JH, Orringer MB, Beer DG. Alterations of K-ras, p53, and erbB-2/neu in human lung adenocarcinomas. J Thorac Cardiovasc Surg. 1994; 107:590-595.

20. Zhou D, Battifora H, Yokota J, Yamamoto T, Cline MJ. Association of multiple copies of the c-erbB-2 oncogene with spread of breast cancer. Cancer Res. 1987;47:6123-6125.

21. Press MF, Pike MC, Chazin VR, et al. Her-2/neu expression in node-negative breast cancer: direct tissue quantitation by computerized image analysis and association of overexpression with increased risk of recurrent disease. Cancer Res. 1993;53:4960-4970.

22. Slamon DJ, Clark GM, Wong SG, Levin WJ, Ullrich A, McGuire WL. Human breast cancer: correlation of relapse and survival with amplification of the HER-2/neu oncogene. Science. 1987;235:177-182.

23. Muss HB, Thor AD, Berry DA, et al. c-erbB-2 expression and response to adjuvant therapy in women with node-positive early breast cancer. $N$ Engl J Med. 1994;330:1260-1266.

24. Gusterson B, Cowley G, McIlhinney J, Ozanne B, Fisher C, Reeves B. Evidence for increased epidermal growth factor receptors in human sarcomas. Int J Cancer. 1985;36:689693.

25. Nielsen TO, West RB, Linn SC, et al. Molecular characteri- sation of soft tissue tumours: a gene expression study. Lancet. 2002;359:1301-1307.

26. Nielsen TO, Hsu FD, O'Connell JX, et al. Tissue microarray validation of epidermal growth factor receptor and SALL2 in synovial sarcoma with comparison to tumors of similar histology. Am J Pathol. 2003;163:1449-1456.

27. Barbashina V, Benevenia J, Aviv $\mathrm{H}$, et al. Oncoproteins and proliferation markers in synovial sarcomas: a clinicopathologic study of 19 cases. J Cancer Res Clin Oncol. 2002;128: 610-616.

28. Allander SV, Illei PB, Chen Y, et al. Expression profiling of synovial sarcoma by cDNA microarrays: association of ERBB2, IGFBP2, and ELF3 with epithelial differentiation. Am J Pathol. 2002;161:1587-1595.

29. Nuciforo PG, Pellegrini C, Fasani R, et al. Molecular and immunohistochemical analysis of HER2/neu oncogene in synovial sarcoma. Hum Pathol. 2003;34:639-645.

30. George E, Niehans GA, Swanson PE, Strickler JG, Singleton TP. Overexpression of the c-erbB-2 oncogene in sarcomas and small round-cell tumors of childhood. An immunohistochemical investigation. Arch Pathol Lab Med. 1992;116: 1033-1035.

31. Fletcher CDM, Unni KK, Mertens F. Pathology and genetics of tumours of soft tissue and bone. Lyon: IARC Press, 2002.

32. Bubendorf L, Nocito A, Moch H, Sauter G. Tissue microarray (TMA) technology: miniaturized pathology archives for high-throughput in situ studies. J Pathol. 2001;195:72-79.

33. Nocito A, Kononen J, Kallioniemi OP, Sauter G. Tissue microarrays (TMAs) for high-throughput molecular pathology research. Int J Cancer. 2001;94:1-5.

34. Wang S, Saboorian MH, Frenkel E, Hynan L, Gokaslan ST, Ashfaq R. Laboratory assessment of the status of Her-2/neu protein and oncogene in breast cancer specimens: comparison of immunohistochemistry assay with fluorescence in situ hybridisation assays. J Clin Pathol. 2000;53:374-381.

35. Inagaki $H$, Murase $\mathrm{T}$, Otsuka $\mathrm{T}$, Eimoto $\mathrm{T}$. Detection of SYT-SSX fusion transcript in synovial sarcoma using archival cytologic specimens. Am J Clin Pathol. 1999;111:528533.

36. Chomczynski P, Sacchi N. Single-step method of RNA isolation by acid guanidinium thiocyanate-phenol-chloroform extraction. Anal Biochem. 1987;162:156-159.

37. Heid CA, Stevens J, Livak KJ, Williams PM. Real time quantitative PCR. Genome Res. 1996;6:986-994.

38. Tanner M, Gancberg D, Di Leo A, et al. Chromogenic in situ hybridization: a practical alternative for fluorescence in situ hybridization to detect HER-2/neu oncogene amplification in archival breast cancer samples. Am J Pathol. 2000;157: $1467-1472$.

39. Zhao J, Wu R, Au A, Marquez A, Yu Y, Shi Z. Determination of HER2 gene amplification by chromogenic in situ hybridization (CISH) in archival breast carcinoma. Mod Pathol. 2002;15:657-665.

40. Thomas DG, Giordano TJ, Sanders D, Biermann JS, Baker L. Absence of HER2/neu gene expression in osteosarcoma and skeletal Ewing's sarcoma. Clin Cancer Res. 2002;8:788-793.

41. Gusterson B, Cowley G, McIlhinney J, Ozanne B, Fisher C, Reeves B. Evidence for increased epidermal growth factor receptors in human sarcomas. Int J Cancer. 1985;36:689-693.

42. Pauletti G, Dandekar S, Rong H, et al. Assessment of methods for tissue-based detection of the HER-2/neu alteration in human breast cancer: a direct comparison of fluorescence in situ hybridization and immunohistochemistry. J Clin Oncol. 2000;18:3651-3664. 
43. Tubbs RR, Pettay JD, Roche PC, Stoler MH, Jenkins RB, Grogan TM. Discrepancies in clinical laboratory testing of eligibility for trastuzumab therapy: apparent immunohistochemical false-positives do not get the message. J Clin Oncol. 2001;19:2714-2721.

44. Press MF, Hung G, Godolphin W, Slamon DJ. Sensitivity of HER-2/neu antibodies in archival tissue samples: potential source of error in immunohistochemical studies of oncogene expression. Cancer Res. 1994;54:2771-2777.

45. Gancberg D, Lespagnard L, Rouas G, et al. Sensitivity of HER-2/neu antibodies in archival tissue samples of invasive breast carcinomas. Correlation with oncogene amplification in 160 cases. Am J Clin Pathol. 2000;113:675-682.

46. Hoang MP, Sahin AA, Ordonez NG, Sneige N. HER-2/neu gene amplification compared with HER-2/neu protein overexpression and interobserver reproducibility in invasive breast carcinoma. Am J Clin Pathol. 2000;113:852-859.

47. Press MF, Cordon-Cardo C, Slamon DJ. Expression of the HER-2/neu proto-oncogene in normal human adult and fetal tissues. Oncogene. 1990;5:953-962.

48. Press MF, Jones LA, Godolphin W, Edwards CL, Slamon DJ. HER-2/neu oncogene amplification and expression in breast and ovarian cancers. Prog Clin Biol Res. 1990;354A: 209-221.

49. Dei Tos AP, Dal Cin P. The role of cytogenetics in the classification of soft tissue tumours. Virchows Arch A. 1997; 431:83-94.

50. Brett D, Whitehouse S, Antonson P, Shipley J, Cooper C, Goodwin G. The SYT protein involved in the $t(X ; 18)$ synovial sarcoma translocation is a transcriptional activator localised in nuclear bodies. Hum Mol Genet. 1997;6:15591564 .
51. Thaete C, Brett D, Monaghan P, et al. Functional domains of the SYT and SYT-SSX synovial sarcoma translocation proteins and co-localization with the SNF protein BRM in the nucleus. Hum Mol Genet. 1999;8:585-591.

52. Eid JE, Kung AL, Scully R, Livingston DM. p300 interacts with the nuclear proto-oncoprotein SYT as part of the active control of cell adhesion. Cell. 2000;102:839-848.

53. Crew AJ, Clark J, Fisher C, et al. Fusion of SYT to two genes, SSX1 and SSX2, encoding proteins with homology to the Kruppel-associated box in human synovial sarcoma. EMBO J. 1995;14:2333-2340.

54. dos Santos NR, Torensma R, de Vries TJ, et al. Heterogeneous expression of the SSX cancer/testis antigens in human melanoma lesions and cell lines. Cancer Res. 2000;60: $1654-1662$.

55. dos Santos NR, de Bruijn DR, Balemans M, et al. Nuclear localization of SYT, SSX and the synovial sarcoma-associated SYT-SSX fusion proteins. Hum Mol Genet. 1997;6:1549-1558.

56. Soulez M, Saurin AJ, Freemont PS, Knight JC. SSX and the synovial-sarcoma-specific chimaeric protein SYT-SSX colocalize with the human Polycomb group complex. Oncogene. 1999;18:2739-2746.

57. Nagai M, Tanaka S, Tsuda M, et al. Analysis of transforming activity of human synovial sarcoma-associated chimeric protein SYT-SSX1 bound to chromatin remodeling factor hBRM/hSNF2 alpha. Proc Natl Acad Sci USA. 2001;98:38433848.

58. Kato $\mathrm{H}$, Tjernberg A, Zhang $\mathrm{W}$, et al. SYT associates with human SNF/SWI complexes and the C-terminal region of its fusion partner SSX1 targets histones. J Biol Chem. 2002;277: 5498-5505. 